\title{
Root Architecture and Genetic Variations Associated with Phosphorus Uptake in Rice
}

\author{
Alogaidi Faez ${ }^{1,2}$, Price Adam ${ }^{1}$, Johnson David ${ }^{1}$ \\ ${ }^{1}$ Institute of Biological and Environmental Sciences, University of Aberdeen, Aberdeen, UK \\ ${ }^{2}$ Present address: Field Crop Department, College of Agriculture, University of Baghdad, Baghdad, Iraq \\ Email address: \\ faezalogaidi@yahoo.com (A. Faez), a.price@abdn.ac.uk (P. Adam),djohnson@abdn.ac.uk (J. David)
}

\section{To cite this article:}

Alogaidi Faez, Price Adam, Johnson David. Root Architecture and Genetic Variations Associated with Phosphorus Uptake in Rice. International Journal of Applied Agricultural Sciences. Vol. 1, No. 1, 2015, pp. 1-10. doi: 10.11648/j.ijaas.20150101.11

\begin{abstract}
Phosphorus (P) is a finite resource and is a major limiting factor for rice yield on a large area of World's arable land. The main objective of this study was to investigate plant and soil P interaction in P limiting conditions. A P deficient $25 / 75 \%$ subsoil/sand mix was determined using pots in a preliminary experiment as to be used for screening 30 rice genotypes (Oryza sativa L.).The experiment was designed using a randomized complete block design to test if shallow and deep-rooted genotypes differ in extracting $\mathrm{P}$ present in soil by using rock phosphate in three treatments: when rock $\mathrm{P}$ was absent or embedded either in a shallow $10 \mathrm{~cm}$ layer or distributed homogenously in soil mix. All treatments were fed with Yoshida's nutrient solution lacking of P (YNS-P). Results indicated that P treatment $\mathrm{x}$ genotype interaction was significant on shoot dry weight (SDW). The addition of rock phosphate especially in shallow $10 \mathrm{~cm}$ layer greatly stimulated plant growth where SDW of plants grown in homogenous $\mathrm{P}$ and shallow $\mathrm{P}$ significantly outgrew those in zero $\mathrm{P}$ treatment. Both $\mathrm{P}$ treatment and genotype affected root dry weight (RDW) and root/shoot ratio significantly. Rice from the aus subgroup grown in zero $\mathrm{P}$ treatment accumulated significantly more SDW than indica and japonica genotypes. In zero P treatment, the genotypes Black Gora, Rayada, Kasalath, Azucena, IAC25, Dom Sufid, Aux1Wild type, FR13A and especially Sadu Cho accumulated higher SDW relative to the others.
\end{abstract}

Keywords: Oryza sativa, Phosphorus Deficiency, Shoot Dry Weight, Root/Shoot Ratio

\section{Introduction}

$\mathrm{P}$ deficiency is a major abiotic stress that limits crop productivity on $30-40 \%$ of the World's arable land (1). $\mathrm{P}$ is limited to plants because of its chemical fixation and low solubility. In most soils, $\mathrm{P}$ availability is therefore suboptimal and inadequate for high yield production. $\mathrm{P}$ is also expensive and the majority of farmers especially in developing countries cannot afford the rising prices of $\mathrm{P}$ fertilizers. So $\mathrm{P}$ availability in soil is a matter of concern and invites research attention to find an alternative way for sustainable production and food security for the world's growing population. Soil resources are usually unevenly distributed in space and time and often subject to localized depletion that make root architecture of great importance for plant productivity (2). For example greater nutrient acquisition especially in case of immobile resources such as $\mathrm{P}$ has been associated with topsoil foraging (3). Plant residues, remaining roots and $\mathrm{P}$ applied as fertilizers constitute the main sources of soil $\mathrm{P}$, most of which is bound by soil particles within the shallow surface layer of the soil. This has made P concentration and availability more at the soil surface than at depth. Therefore, genotypes with a deep rooted system may lose the opportunity to access shallow $\mathrm{P}$ and hence root class may be of great importance in terms of $\mathrm{P}$ uptake. Root systems are made of a complex array of distinguishable root classes $(4 ; 5)$. The spatial distribution of root system dictates the nature and function of each root class. Different root classes tap different soil areas, and through their interaction with the surrounding soils are subjected to different external effects. Therefore, they may differ in their capacity for nutrient absorption. For example, adventitious roots with greater intrinsic P influx capacity would benefit the plant as this root class generally forages the topsoil where the greater part of available soil $\mathrm{P}$ is located $(6 ; 7 ; 8)$. Thus, in considering the limited availability of $\mathrm{P}$, it is imperative to explore the root traits that enable $\mathrm{P}$ efficient genotypes to grow well in low and/or stratified availability of P. Most researchers and plant breeders endeavour to evaluate phosphorus use efficiency (PUE) for crop species and genotypes that are promising to 
fulfill the economic and agronomic purposes for sustainable agricultural production with low inputs and which offer a more environmentally friendly solution to sustainability. Selection of genotypes with high PUE is essential to sustain productivity with low-inputs. Therefore, exploring the genetic variations of adaptive responses among crop species and genotypes for enhanced $\mathrm{P}$ efficiency and soil $\mathrm{P}$ acquisition ensures sustainable agricultural production in $\mathrm{P}$ limiting soils. Against this background, this study was designed to screen different rice genotypes aiming at evaluating genotypic differences in P uptake and PUE under P limiting soil. Therefore the objective of this study was to investigate whether the distribution (shallow or homogenous) of $\mathrm{P}$ applied as rock phosphate through soil profile affects rice growth and the following hypotheses will be tested;

- Shallow P is more available to rice plants than evenly distributed P.

- Rice genotypes differ in their ability to get P out of soil.

- Shallow rooting genotypes have an advantage over deep rooted varieties when growth is limited by $\mathrm{P}$ that is available only in the top of the soil, but not if it is evenly distributed.

\section{Material and Methods}

\subsection{Determination of Plant Available and Totalp in Soil}

Available $\mathrm{P}$ in the soil was estimated by using acetic acid extraction as described by Allen (9). Five g, in four replicates, of each four air-dried soils were weighed into $250 \mathrm{ml}$ conical flasks then $150 \mathrm{ml}$ of extractant $(2.5 \% \mathrm{v} / \mathrm{v}$ acetic acid $)$ was added. The soil samples and blank flasks were shaken for two hours on a rotary shaker, and then allowed to settle overnight. The clear supernatant was then filtered through Whatman No. 40 paper into centrifuge tubes and the first 5$10 \mathrm{ml}$ of filtrate was rejected. $\mathrm{P}$ was determined in the remaining filtrate of all samples. $\mathrm{P}$ concentration was measured by colorimetric analysis using the automated spectrophotometric flow injection analyzer (FIA). P content was calculated by multiplying soil dry weights with $\mathrm{P}$ concentrations. Results are demonstrated in Table 1. The available $\mathrm{P}$ in soil can be classified based on Bray P1 test, as defined by Marx et al. (10): < $20 \mathrm{mg} \mathrm{kg-1}$ as low, 20-40 mg $\mathrm{kg}-1$ as medium, 40-100 mg kg-1 as high and $>100 \mathrm{mg} \mathrm{kg-1}$ as excessive. Accordingly, the soil test result for available $\mathrm{P}$ in Insch subsoil used in this experiment is $12.24 \mathrm{mg} \mathrm{kg}-1$ indicating that it is low. As for total $\mathrm{P}$ in soil, the soil were ground in stainless steel ball mill (Retsch MM200), after being oven dried at $70{ }^{\circ} \mathrm{C}$ for 48 hours. $4.5 \mathrm{ml}$ of digest reagent $(2.8 \mathrm{ml}$ of concentrated sulphuric acid, $0.08 \mathrm{~g}$ of lithium sulphate and $2.33 \mathrm{ml}$ hydrogen peroxide) was added to approximately $0.2 \mathrm{~g}$ of oven dried, finely ground sample of each soil and heated to $360{ }^{\circ} \mathrm{C}$ for 2 hour to allow digestion. After this time $1 \mathrm{ml}$ of hydrogen peroxide was again added and further digested for an hour. To determine total $\mathrm{P}$ in soil, the diluted digest then underwent FIA. Based on the concentration of $\mathrm{P}$ present in the soil, total $\mathrm{P}$ in soil was determined by multiplying P concentration (mg g-1) in soil with soil dry weight $(\mathrm{g})$.

Table 1. Plant available and total $P$ in the sand and subsoil used in the experiment. Mean of 4 replicates \pm standard deviation.

\begin{tabular}{lll}
\hline & Available $\mathbf{P}\left(\boldsymbol{\mu} \mathbf{g ~ g}^{-1}\right)$ & Total $\mathbf{P}\left(\boldsymbol{\mu} \mathbf{g ~ g}^{-1}\right)$ \\
\hline sand & $1.95 \pm 0.08$ & $12.2 \pm 5.9$ \\
subsoil & $12.24 \pm 0.63$ & $814 \pm 59$ \\
\hline
\end{tabular}

\subsection{Determination of Total Phosphorus and Nitrogen (N) in Plant}

To determine total $\mathrm{P}$ and $\mathrm{N}$ in plant, the procedure described above in section2.1. Determination of plant available and total $\mathrm{P}$ in soil was used (11). Based on the concentration of each element present in the shoot, total each element in shoot was determined by multiplying element concentration (mg g-1) in shoot with shoot dry weight (g). P use efficiency was calculated by dividing shoot dry weight (g) by total $\mathrm{P}$ in shoot (mg).

\subsection{Rice Genotype Selection}

In a preliminary experiment (data not shown), only one genotype (Azucena) was chosen to be grown. A total of 30 different rice genotypes were used which were mostly obtained from the International Rice Research Institute. Twenty of the genotypes belong to the Oryza SNP set (12): Akihikari, Aswina, Azucena, Bala, Black Gora, CT 9993, Cypress, Dom Sufid, Dular, FR13A, IAC165, IAC25, IR64, Kinandang Patong, Labelle, Lemont, Kasalath, Li-Jiang-XinTuan-Hei-Gu, Moroberekan, N22, Nipponbare, Rayada, Sadu Cho, Sanhuangzhan No 2, Swarna, Tainung 67 and Zhenshan 97. This Oryza SNP panel was selected because they have received extensive genetic (12) and phenotypic (13) studies. Two genotypes are mutants of the Auxl gene which is known to affect root growth (Aux1Mutant 1 and Aux1Mutant 2) while the genotype called Aux1 Wild type is genotype Zhonghua 11 in which genotype the mutants were made.

\subsection{Preparation of Rice Seeds for Germination}

Seed of rice cultivars were surface sterilized in $1 \%$ sodium hypochlorite for two minutes then washed under running tap water before being soaked in a beaker filled with tap water for 5 minutes. The seeds were placed on wet filter paper in a Petri dish, which was sealed with Para film then kept in an incubator at a temperature of $30^{\circ} \mathrm{C}$ for two days.

\subsection{Experimental Design and Growing the Plants}

In controlled growth room of the Cruickshank Building at the School of Biological Sciences, University of Aberdeen, UK, a box experiment was conducted during the winter season from January to March 2012. The growth room was supplied with two automatic vents for intake of fresh air and control temperature. The fresh supply of air was continuously circulated by two fans. The light in the room was supplied by fluorescent grow light. A total of 30 rice genotypes were evaluated for their growth response in a mixture of $25 \% \mathrm{P}$ - 
limited (814 $\mu \mathrm{g}$ g-1dw) Insch subsoil uniformly added to $75 \%$ produce the corrected data.

blast sand $(\mathrm{P}$ content $=12.2 \mu \mathrm{g} \mathrm{g}-1 \mathrm{dw})$. The experiment was when two levels of rock phosphate treatment were used. The first of the P treatments was by adding $59 \mathrm{mg}$ of phosphorus pentoxide (P2O5) per plant to the soil mixture, achieved by adding $200 \mathrm{mg}$ rock phosphate per plant that was distributed homogenously throughout soil profile (homogenous $\mathrm{P}$ ). The second treatment was created where the same amount of rock phosphate (200 mg plant-1) was given in a band in the $10 \mathrm{~cm}$ surface layer (shallow P), while the control treatment had no $\mathrm{P}$ added to the soil mixture (zero $\mathrm{P}$ ). The experiment was conducted using a randomized complete block design (RCBD) with three replicate blocks (boxes) for each treatment, with two plants of each genotype in each box arranged in two randomized sub-blocks. At the bottom of each box $(53 \times 33 \mathrm{~cm}$ at the top, $49 \times 27 \mathrm{~cm}$ at the bottom and $39 \mathrm{~cm} \mathrm{depth}$ ), five drainage holes of five $\mathrm{mm}$ diameter were introduced then a non-woven fabric (Teram, UK) sheet was placed inside. The Insch subsoil and sand were thoroughly mixed and distributed among clear 60 litre plastic boxes. A total of nine boxes were prepared and a plastic sheet (52 x $32 \mathrm{~cm}$ length $\times$ width) was place on the soil surface; the plastic sheets had 60 perforations ( $2 \mathrm{~cm}$ diameter) for sowing plants maintaining a $5 \times 5 \mathrm{~cm}$ distance. A black/white plastic sheet was wrapped around the box to prevent heat gain and light entry. Before sowing, each box was saturated with eight liters of Yoshida's nutrient solution ( $\mathrm{pH} 5.5$ ) (14) without $\mathrm{P}$ (YNS-P). Seeds were surface sterilized in diluted bleach $(1 \%$ $\mathrm{Na}$ hypochlorite) before being germinated at $30 \mathrm{oC}$ for two days. Two pre-germinated, uniform and healthy seedlings for each genotype were sown in each hole. At the second leaf stage, the seedlings were thinned to one per hole. Each box was watered with four liters of YNS-P, three times a week for the first two weeks and five liters three times a week for another two weeks. In the final week, four liters of nutrient solution a day were supplied until harvested on day 35 so that each plant was supplied with 1.5 liters of YNS-P. To minimize the accumulation of nutrients in the growth medium, each box was watered with six liters of deionizer water once a week. Plants were grown in a controlled condition in a growth room under a 12 hour light regime with a light intensity of approximately 350-400 $\mu$ molm- 2 s- 1 photosynthetically active radiation with $25 \pm 2 \mathrm{oC}$ at night and $28 \pm 2 \mathrm{oC}$ in the day. Relative humidity was maintained between 55 and $70 \%$ throughout. Weeds were controlled by hand weeding. Plant height was monitored on weekly basis. After 35 days the plants were harvested and the shoot samples were oven-dried for two days at $70 \mathrm{oC}$ to constant weight and the SDW was measured. Before analysis, each box was treated as two randomized replicate blocks and the mean for each genotype per box was calculated. The resulting data (one value for each genotype in a box) were treated as a randomized complete block with three replicates. The effect of block on traits was assessed by analysis of variance and data were checked for normality and log transformed when needed by producing residuals of the data then adding these residuals to the mean of these data to

\section{Results and Discussion}

An experiment (data not shown) was conducted to determine a suitable medium for larger screens of rice genotypes in response to $\mathrm{P}$ treatments. The $25 / 75 \%$ subsoil/sand mix was selected to be used as a growth medium in the main experiment because this treatment appeared to be the most severely low P treatment that still supported some continued slow growth over the five week period. After this, experiment on the response of 30 rice genotypes were conducted in large storage boxes. The plants were sown in the box maintaining five centimeters between each other in order to minimize the box size that can accommodate a large number of genotypes. There is one limitation with this is that the more the plants grow the more the competition will be. To minimize both the competition among plants and the need for a large box and in the meantime to allow the genetic variations to be expressed, the duration of the experiment conducted here was only five weeks. Nonetheless, it is highly likely that above and below ground competition will be operating in this experiment. Below ground may not be unwelcome since it may emphasize the relative ability of genotypes to access the growth limiting P. Above ground competition is not welcome and it would be useful to verify some of these genotype differences detected here in larger pots where above ground competition could be minimized.

Figure 1 shows representative boxes of three treatments (zero $\mathrm{P}$, shallow $\mathrm{P}$ and homogenous $\mathrm{P}$ ) as they display differences in shoot growth between treatments. In shallow $\mathrm{P}$ treatment, plants exhibit healthy growth with wide, long and light green coloured leaves while zero $\mathrm{P}$ treatment-grown plants are shorter with narrower and dark green coloured leaves, thin stem and reduced numbers of tillers. As for plant growth in homogenous $\mathrm{P}$, it was somewhat between the other two treatments. $\mathrm{P}$ addition greatly stimulated growth in both treatments (homogenous $\mathrm{P}$ and shallow $\mathrm{P}$ ). For example SDW increased by 1.9 times in homogenous $\mathrm{P}$ and 2.9 times in shallow $\mathrm{P}$ treatment compared to that in zero $\mathrm{P}$ treatment (Table 2).

When $\mathrm{P}$ was applied as rock phosphate either homogenously or as a shallow layer of $10 \mathrm{~cm}$ depth, It was expected that whether homogenously or in shallow layer the addition of rock phosphate to the soil profile would increase total plant mass. It was also expected that the partitioning of carbon between roots and shoots will be one of the most important mechanisms that determines plant performance in $\mathrm{P}$ limiting conditions and that the relative performance of genotypes might differ depending on the distribution of $\mathrm{P}$ throughout soil profile. The results reported here are consistent with these predictions. Plant growth was greatly stimulated by the addition of rock phosphate where SDW in both homogenous $\mathrm{P}$ and shallow P increased by 1.9 and 2.9 times compared to that in zero P treatment, where for SDW, general linear model of ANOVA revealed that there was a significant genotype by $\mathrm{P}$ treatment interaction $(\mathrm{P}=0.014)$ 
with both factors had a significant $(\mathrm{P}<0.001)$ effect. This pattern of the significant genotype by treatment interaction and effect was also observed for number of tillers at day 35 with $\mathrm{R} 2$ value at about $71 \%$. There was more tillering in shallow, then homogenous and finally zero $\mathrm{P}$ treatment. The significant genotype by $\mathrm{P}$ treatment interaction for SDW supports the hypothesis that rice genotypes differ in their ability to get $\mathrm{P}$ out of soil. There were very strong correlations (Table 3) between SDW and total P uptake within each treatment indicative of an important role for $\mathrm{P}$ in plant growth in this experiment. Of course, the correlations could reflect an important role of plant growth in obtaining P, but distinguishing the cause and effect here will be very difficult. The significant $(\mathrm{P}<0.001, \quad \mathrm{~F}=41.62, \quad \mathrm{R} 2=19 \%)$ increase in SDW of shallow $\mathrm{P}$ compared to homogenous $\mathrm{P}$ treatment supports the hypothesis that shallow $\mathrm{P}$ is more available to rice plants than evenly distributed P. Thus shallow rooting genotypes should have a greater advantage over deep rooted genotypes when growth is limited by $\mathrm{P}$ that is available only in the top of the soil.

Both shoot length and RDW were affected significantly $(\mathrm{P}<0.001)$ by $\mathrm{P}$ treatment and genotype but no significant interaction between these two factors was found. R2 value for both factors was $62 \%$ in RDW and $86 \%$ in shoot length. As for RDW, it increased by 1.4 in homogenous $\mathrm{P}$ and 1.8 times in shallow $\mathrm{P}$ treatment compared to that in zero $\mathrm{P}$ treatment. Most importantly, as can be clearly seen in the bar chart (Figure 2), all genotypes in zero $\mathrm{P}$ had higher root/shoot ratio than homogenous $\mathrm{P}$ and in the latter there was more root/shoot ratio than in shallow $\mathrm{P}$ treatment. Two way ANOVA revealed a significant $(\mathrm{P}<0.001)$ interaction for root/shoot ratio with both $\mathrm{P}$ treatment and genotype had a significant $(\mathrm{P}<0.001)$ effect.

In zero $\mathrm{P}$ treatment, the subgroup effect was significant $(\mathrm{P}<0.001, \mathrm{~F}=9.21)$ on SDW and on average, aus subgroup had 1.2 and 1.4 fold more SDW than indicas and Japonicas respectively, which suggest that for the genotypes used in this study, aus subgroup are more tolerant to P deficiency than indicas and Japonicas(Table 2). On the other hand, the SDW of both indicas and Japonicas increased by $55 \%$ in shallow $\mathrm{P}$ treatment relative to homogenous $\mathrm{P}$ treatment while the increase of aus genotypes was only $50 \%$. This indicates that genotypes belonged to aus subgroup had less shallow roots than either indicias or Japonicas and is in consistent with what is known about aus subgroup as deep rooted genotypes (15). It can be suggested that both Indicas and Japonicas had a greater ability to take up shallow $\mathrm{P}$ in soil than aus subgroup while the latter may had more P efficiency when grown in $\mathrm{P}$ deficient conditions. Figure 3 demonstrates plotted data of SDW in shallow $\mathrm{P}$ vs SDW in zero $\mathrm{P}$ treatment. By examining this plot, a general statement can be made that two main categories of genotypes can be considered according to their $\mathrm{P}$ treatment response. A first category of genotypes that falls below the line that are relatively tolerant for $\mathrm{P}$ deficiency especially those belong to aus subgroup (Black Gora, Rayada, Kasalath and FR13A) and the Aux1Wild type, which were notable by having a higher SDW in zero $\mathrm{P}$ treatment than predicted by their SDW in shallow $\mathrm{P}$ treatment. On the other hand, all genotypes occupied their position above the line are responsive to $\mathrm{P}$ in shallow layer (category two). The indica genotype Sadu Cho seems to be substantially superior to all genotypes in all treatments. In homogenous P treatment, RDW for genotypes belonging to both aus and indica was slightly above the average by $5.6 \%$ and $8.9 \%$ respectively.

Table 4 shows results from the analysis of variance for the data recorded from root scanning. The rock phosphate treatment and genotype had a significant $(\mathrm{P}<0.001)$ effect upon root surface area and volume but not on root length or root tips and there were no interactions for all traits measured. A significant $(\mathrm{P}<0.001$ and $\mathrm{P}=0.005)$ effect for $\mathrm{P}$ treatment on specific root length [root length $(\mathrm{m}) / \mathrm{RDW}(\mathrm{g})$ ] and average diameter respectively were found. The specific root length decreased by $18.2 \%$ in shallow $\mathrm{P}$ while in zero $\mathrm{P}$ increased by $75.5 \%$ compared to that in homogenous $\mathrm{P}$ treatment. Likewise, the average diameter in shallow $\mathrm{P}$ increased by $17 \%$ while in zero $\mathrm{P}$ decreased by $7.3 \%$ compared to that in homogenous $\mathrm{P}$ treatment.

$P$ concentration in eleven selected rice genotypes was measured. When the mean of SDW and plant P status were tested for correlation using the Pearson correlation coefficient, it was found that within each treatment there is very strong correlation between SDW and total P uptake. $r=0.941,0.951$ and 0.875 in homogenous, shallow and zero $\mathrm{P}$ treatment respectively (Table 3 ). Table 5 demonstrates the output of analysis of variance for $\mathrm{P}$ status in eleven genotypes. There were massive genotype and treatment effects $(\mathrm{P}<0.001)$ on $\mathrm{P}$ concentration but no interaction was found. In general, $[\mathrm{P}]$ increased in shallow $\mathrm{P}$ by 1.5 times while it decreased by half in zero $\mathrm{P}$ compared to homogenous $\mathrm{P}$ treatment. Kasalath and to some extent black Gora has low $[\mathrm{P}]$ in the rock $\mathrm{P}$ treatments. [P] of Aux1Mutant1 and Aux1Mutant 2 is lower than Auxlwild type except in shallow $\mathrm{P}$ where trend is reversed, but unfortunately only the treatment effect is significant when just these three genotypes were used. For both total $\mathrm{P}$ in shoot and PUE [SDW $(\mathrm{g}) /$ total $\mathrm{P}$ in shoot $(\mathrm{mg})$ ], a significant $(\mathrm{P}<0.05)$ interaction was found with both $\mathrm{P}$ treatment and genotype affecting both traits in a highly significant $(\mathrm{P}<0.001)$ manner. On average, genotypes in shallow $\mathrm{P}$ treatment absorbed only 2.2 times more $\mathrm{P}$ than in homogenous $\mathrm{P}$ and 9.1 times more than the zero $\mathrm{P}$ treatment respectively. Azucena and IAC25 have high $\mathrm{P}$ per plant except in low $\mathrm{P}$ treatment. When SDW is plotted against PUE, there is a trend for the high mass plants to have high $\mathrm{P}$ efficiency and vice versa (Figure 4). The two genotypes Azucena and IAC25, which belong to Japonica subspecies, occupied their position as having higher SDW and higher $\mathrm{P}$ efficiency than the rest while Aux1 Mutant1, Aux1 Mutant2 and Nipponbare are the lowest in both SDW and P efficiency. The genotype Aux1Wild type had a low P efficiency but a high mass especially in homogenous $\mathrm{P}$ and zero $\mathrm{P}$ treatments. Using Pearson correlation coefficient the RDW was found to be correlated significantly $(\mathrm{r}=0.868, \mathrm{P}=0.001$ and $\mathrm{r}=0.883$, $\mathrm{P}<0.001$ ) with total $\mathrm{P}$ in shoot in both homogenous $\mathrm{P}$ and 
shallow $\mathrm{P}$ treatments respectively while in zero $\mathrm{P}$ treatment do not. This can clearly be seen in Figure 5.

Both $\mathrm{P}$ treatment and genotype significantly affected root mass. RDW in shallow $\mathrm{P}$ and homogenous $\mathrm{P}$ was significantly more than that in zero $\mathrm{P}$. These results are consistent with Drew (16) and Drew and Saker (17). The authors studied the relationship between growth and nutrient supply and found that if nutrients such as nitrate, ammonium and phosphate are differentially available to parts of the root system, the part with the greater supply grows more. The effect of $\mathrm{P}$ treatment on specific root length [root length $(\mathrm{m}) / \mathrm{RDW}(\mathrm{g})$ ] was significant where the specific root length in shallow P decreased by $18.2 \%$ while in zero P increased by $75.5 \%$ compared to that in homogenous $\mathrm{P}$ treatment. This means that $\mathrm{P}$ deficiency reduced root diameter of plant (the less $\mathrm{P}$ available in soil is, the finer the root will be). Indeed, $\mathrm{P}$ treatment was found to have a significant effect on average diameter of the root (Table 4). This finding is in consistent with results presented by Fitter (18) and Hill et al. (19) who showed that many species adjusting to low $\mathrm{P}$ conditions concurrently increase specific root length to achieve longer or more branched roots per unit of root mass. It is logical to predict that all the treatments used in this experiment would alter the partitioning between roots and shoots. Genotypes with shallow roots would be expected to benefit from $\mathrm{P}$ in shallow layers of the soil. Under edaphic stress, especially when facing P deficiency, roots must explore a large volume of soil. Under low P conditions, the plant therefore allocates more photosynthates towards the roots than to shoots $(20 ; 5)$. The significant effect of genotype and $\mathrm{P}$ treatment on both SDW and RDW was reflected in an effect on root/shoot ratio, where all genotypes had significantly higher root/shoot ratio in zero $\mathrm{P}$, then homogenous $\mathrm{P}$ and the lower root/shoot ratio was in shallow $\mathrm{P}$ treatment. This clearly demonstrates the effect of $\mathrm{P}$ stress on all genotypes in zero $\mathrm{P}$ that make the plant allocate more metabolites towards the roots in order to access limited soil P by exploring more soil volume. On the other hand, the closely embedded rock phosphate in the shallow $\mathrm{P}$ treatment allow the plants to take up more $\mathrm{P}$ and consequently allocate less carbon (metabolites) in the root than plants grown in both homogenous $\mathrm{P}$ and zero $\mathrm{P}$ treatments.

\section{Conclusion}

Evidence presented here indicates that rice genotypes interact strongly with $\mathrm{P}$ added in rock phosphate experiment for almost all growth parameters and $\mathrm{P}$ uptake indicating that they differ significantly in their ability for $\mathrm{P}$ uptake and growth under low P. This study gave evidence that shallow rooting genotypes have the opportunity to grow better than deep rooted genotypes when growth is limited by $\mathrm{P}$ that is available only in the top of the soil. From a practical perspective, genotypes like Black Gora, Rayada, Kasalath, Azucena, IAC25, Dom Sufid, Aux1Wildtype, FR13A and especially Sadu Cho are outstanding as they perform well in these screens including when soil $\mathrm{P}$ is very low. These genotypes can be used in breeding programs and should attract more research attention to find more about mechanisms behind their superiority for P uptake and PUE.

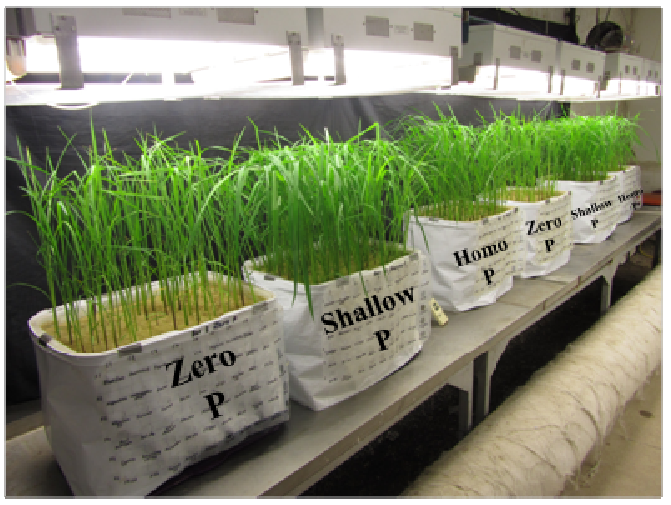

Figure 1. Growing rice genotypes in plastic boxes in the growth room.

Table 2. Analysis of variance and average parameters of plant growth parameters for 29 rice genotypes grown in a 25/75\% subsoil/sand mix either with (homogenous $P$ or shallow $P$ ) or without rock phosphate (zero $P$ ) as a control. Mean $=6$.

\begin{tabular}{|c|c|c|c|c|c|c|c|}
\hline \multirow[b]{2}{*}{ Genotypes } & \multirow[b]{2}{*}{ Subgroup } & \multicolumn{3}{|c|}{ Shoot length day $35(\mathrm{~cm})$} & \multicolumn{2}{|c|}{ SDW (mg) } & \multirow[b]{2}{*}{ Zero } \\
\hline & & Homo & Shallow & Zero & Homo & Shallow & \\
\hline FR $13 \mathrm{~A}$ & aus & 67.6 & 74.7 & 60.3 & 724 & 995 & 380 \\
\hline Rayada & aus & 72.6 & 80 & 60.1 & 529 & 791 & 304 \\
\hline Kasalath & aus & 63.1 & 70.9 & 56.5 & 439 & 758 & 301 \\
\hline Black Gora & aus & 61.5 & 66.8 & 56 & 476 & 758 & 273 \\
\hline Dular & aus & 63.9 & 72.2 & 54.4 & 466 & 735 & 241 \\
\hline N22 & aus & 64.4 & 72.8 & 51.3 & 386 & 508 & 229 \\
\hline Sadu Cho & IND & 65.7 & 71.5 & 55 & 954 & 1569 & 414 \\
\hline Aswina & IND & 72.3 & 80.6 & 62 & 495 & 688 & 287 \\
\hline Bala & IND & 63.6 & 72.1 & 49.9 & 469 & 792 & 246 \\
\hline Kinandang Patong & IND & 59 & 65 & 49 & 517 & 651 & 233 \\
\hline IR 64 & IND & 50.6 & 59.2 & 46.2 & 505 & 760 & 212 \\
\hline Zhenshan 97 & IND & 51.9 & 57.3 & 45.4 & 267 & 595 & 211 \\
\hline Swarna & IND & 51.5 & 57 & 42.6 & 386 & 443 & 194 \\
\hline indica mean & & 57.7 & 64.1 & 48.9 & 488 & 758 & 249 \\
\hline Azucena & TRJ & 74.9 & 80.4 & 58.8 & 733 & 1034 & 328 \\
\hline IAC 25 & TRJ & 73.4 & 81.7 & 56 & 657 & 1127 & 327 \\
\hline IAC 165 & TRJ & 62.8 & 70.4 & 51.4 & 442 & 742 & 238 \\
\hline
\end{tabular}




\begin{tabular}{|c|c|c|c|c|c|c|c|c|c|}
\hline \multirow[b]{2}{*}{ Cypress } & \multirow[b]{2}{*}{ TRJ } & \multicolumn{4}{|c|}{ Shoot length day $35(\mathrm{~cm})$} & \multicolumn{3}{|c|}{ SDW (mg) } & \multirow[b]{2}{*}{199} \\
\hline & & 57 & 65.4 & & 48.4 & 334 & 538 & & \\
\hline Moroberekan & TRJ & 65.6 & 73.7 & & 53.4 & 442 & 693 & & 251 \\
\hline Lemont & TRJ & 60.7 & 67.7 & & 45.1 & 360 & 498 & & 170 \\
\hline Labelle & TRJ & 50.2 & 54.7 & & 42.6 & 297 & 492 & & 151 \\
\hline Li-Jiang-Xin-Tuan-Hei-Gu & TEJ & 67.5 & 70.7 & & 57.2 & 523 & 784 & & 263 \\
\hline Nipponbare & TEJ & 57.6 & 62.4 & & 45.8 & 446 & 523 & & 183 \\
\hline Tainung 67 & TEJ & 49.4 & 65.2 & & 45.2 & 278 & 411 & & 172 \\
\hline Akihikari & TEJ & 53.1 & 59.5 & & 38.9 & 152 & 380 & & 138 \\
\hline Japonica mean & - & 61.1 & 68.3 & & 49.3 & 424 & 657 & & 220 \\
\hline Aux1 Wild type & - & 62.1 & 65.7 & & 53.5 & 568 & 752 & & 297 \\
\hline Aux1Mutant 1 & - & 56.1 & 65.1 & & 45.9 & 351 & 616 & & 177 \\
\hline Aux1Mutant 2 & - & 43.3 & 55.1 & & 40.5 & 245 & 348 & & 149 \\
\hline Dom Sufid & aromatic* & 67.9 & 78.4 & & 56.5 & 655 & 925 & & 312 \\
\hline Mean & & 60.6 & 67.8 & & 50.7 & 463 & 705 & & 245 \\
\hline \#ANOVA & & $\mathrm{F}$ & & $P$ & & $\mathrm{~F}$ & & $P$ & \\
\hline $\mathrm{T}(2)$ & & 381.03 & & 0.000 & & 235.82 & & 0.000 & \\
\hline G (28) & & 30.89 & & 0.000 & & 11.54 & & 0.000 & \\
\hline TxG (56) & & 1.14 & & 0.258 & & 1.57 & & 0.014 & \\
\hline $\mathrm{R}^{2}$ & & $86.06 \%$ & & & & $75.40 \%$ & & & \\
\hline
\end{tabular}

Table 2. Continue.

\begin{tabular}{|c|c|c|c|c|c|c|c|c|c|c|}
\hline \multirow[b]{2}{*}{ Genotypes } & \multirow[b]{2}{*}{ Subgroup } & \multicolumn{3}{|c|}{ Number of tillers day 35} & \multicolumn{3}{|c|}{ RDW (mg) } & \multicolumn{3}{|c|}{ Root/shoot ratio } \\
\hline & & Homo & Shallow & Zero & Homo & Shallow & Zero & Homo & Shallow & Zero \\
\hline FR $13 \mathrm{~A}$ & aus & 1 & 2 & 0 & 225 & 230 & 148 & 0.31 & 0.23 & 0.41 \\
\hline Rayada & aus & 1.6 & 2.33 & 1.25 & 195 & 181 & 155 & 0.37 & 0.27 & 0.51 \\
\hline Kasalath & aus & 0.83 & 1.83 & 1 & 118 & 151 & 44 & 0.30 & 0.25 & 0.32 \\
\hline Black Gora & aus & 0.83 & 1.17 & 0 & 130 & 133 & 137 & 0.34 & 0.27 & 0.44 \\
\hline Dular & aus & 0.5 & 1.83 & 0 & 189 & 219 & 120 & 0.37 & 0.27 & 0.51 \\
\hline N22 & aus & 1 & 1.5 & 0 & 144 & 214 & 119 & 0.51 & 0.37 & 0.61 \\
\hline Sadu Cho & IND & 2.83 & 4 & 1 & 279 & 410 & 196 & 0.28 & 0.23 & 0.51 \\
\hline Aswina & IND & 1.25 & 1.67 & 0.5 & 172 & 238 & 167 & 0.38 & 0.31 & 0.53 \\
\hline Bala & IND & 1.5 & 2.17 & 0.33 & 136 & 222 & 106 & 0.34 & 0.30 & 0.44 \\
\hline Kinandang Patong & IND & 0.67 & 1.17 & 0 & 222 & 221 & 121 & 0.45 & 0.34 & 0.58 \\
\hline IR 64 & IND & 1.83 & 3.33 & 1 & 154 & 212 & 70 & 0.31 & 0.24 & 0.34 \\
\hline Zhenshan 97 & IND & 1 & 1.67 & 0 & 164 & 233 & 120 & 0.43 & 0.34 & 0.56 \\
\hline Swarna & IND & 1.33 & 1.67 & 0 & 135 & 148 & 57 & 0.38 & 0.30 & 0.39 \\
\hline Sanhuangzhan No 2 & IND & 1.33 & 2.5 & 0.33 & 113 & 163 & 79 & 0.33 & 0.28 & 0.50 \\
\hline Azucena & TRJ & 0.67 & 1.83 & 0 & 229 & 344 & 128 & 0.36 & 0.27 & 0.37 \\
\hline IAC 25 & TRJ & 0.67 & 1.67 & 0 & 192 & 244 & 140 & 0.34 & 0.24 & 0.42 \\
\hline IAC 165 & TRJ & 0 & 1.17 & 0 & 187 & 239 & 130 & 0.40 & 0.36 & 0.57 \\
\hline Cypress & TRJ & 1 & 1.33 & 0 & 168 & 141 & 110 & 0.42 & 0.28 & 0.48 \\
\hline Moroberekan & TRJ & 0.33 & 1.17 & 0 & 191 & 217 & 128 & 0.44 & 0.26 & 0.49 \\
\hline Lemont & TRJ & 0.2 & 1 & 0 & 142 & 216 & 110 & 0.44 & 0.33 & 0.66 \\
\hline Labelle & TRJ & 0 & 0.33 & 0 & 129 & 211 & 80 & 0.37 & 0.32 & 0.52 \\
\hline Li-Jiang-Xin-Tuan-Hei-Gu & TEJ & 2 & 2.6 & 0 & 133 & 375 & 135 & 0.33 & 0.23 & 0.53 \\
\hline Nipponbare & TEJ & 1.5 & 2 & 0 & 117 & 87 & 47 & 0.26 & 0.19 & 0.27 \\
\hline Tainung 67 & TEJ & 0.8 & 1.17 & 0 & 106 & 123 & 56 & 0.33 & 0.31 & 0.35 \\
\hline Akihikari & TEJ & 0.2 & 1.6 & 0 & 70 & 116 & 73 & 0.33 & 0.30 & 0.43 \\
\hline Japonica mean & - & 0.67 & 1.44 & 0.00 & 151 & 210 & 103 & 0.37 & 0.28 & 0.46 \\
\hline Aux 1 Wild type & - & 2 & 2.17 & 0.5 & 143 & 198 & 166 & 0.29 & 0.29 & 0.54 \\
\hline Aux1Mutant 1 & - & 1.67 & 2 & 0 & 107 & 165 & 85 & 0.34 & 0.27 & 0.53 \\
\hline Aux1Mutant 2 & - & 0.5 & 1.33 & 0 & 83 & 121 & 119 & 0.42 & 0.30 & 0.83 \\
\hline Mean & & 1.04 & 1.79 & 0.21 & 158 & 206 & 113 & 0.36 & 0.28 & 0.49 \\
\hline \#ANOVA & & $\mathrm{F}$ & $P$ & & $\mathrm{~F}$ & $P$ & & $\mathrm{~F}$ & $P$ & \\
\hline $\mathrm{T}(2)$ & & 207.50 & & & 58.42 & & & 41.24 & & \\
\hline G (28) & & 7.79 & & & 6.55 & & & 7.41 & & \\
\hline TxG (56) & & 1.45 & & & 1.10 & & & 2.20 & & \\
\hline $\mathrm{R}^{2}$ & & $70.74 \%$ & & & $62.10 \%$ & & & $38.92 \%$ & & \\
\hline
\end{tabular}

\# ANOVA output and $\mathrm{R}^{2}$; T, rock phosphate treatment; G, genotype (29); degrees of freedom between brackets. The factors and interactions in bold are significant. 


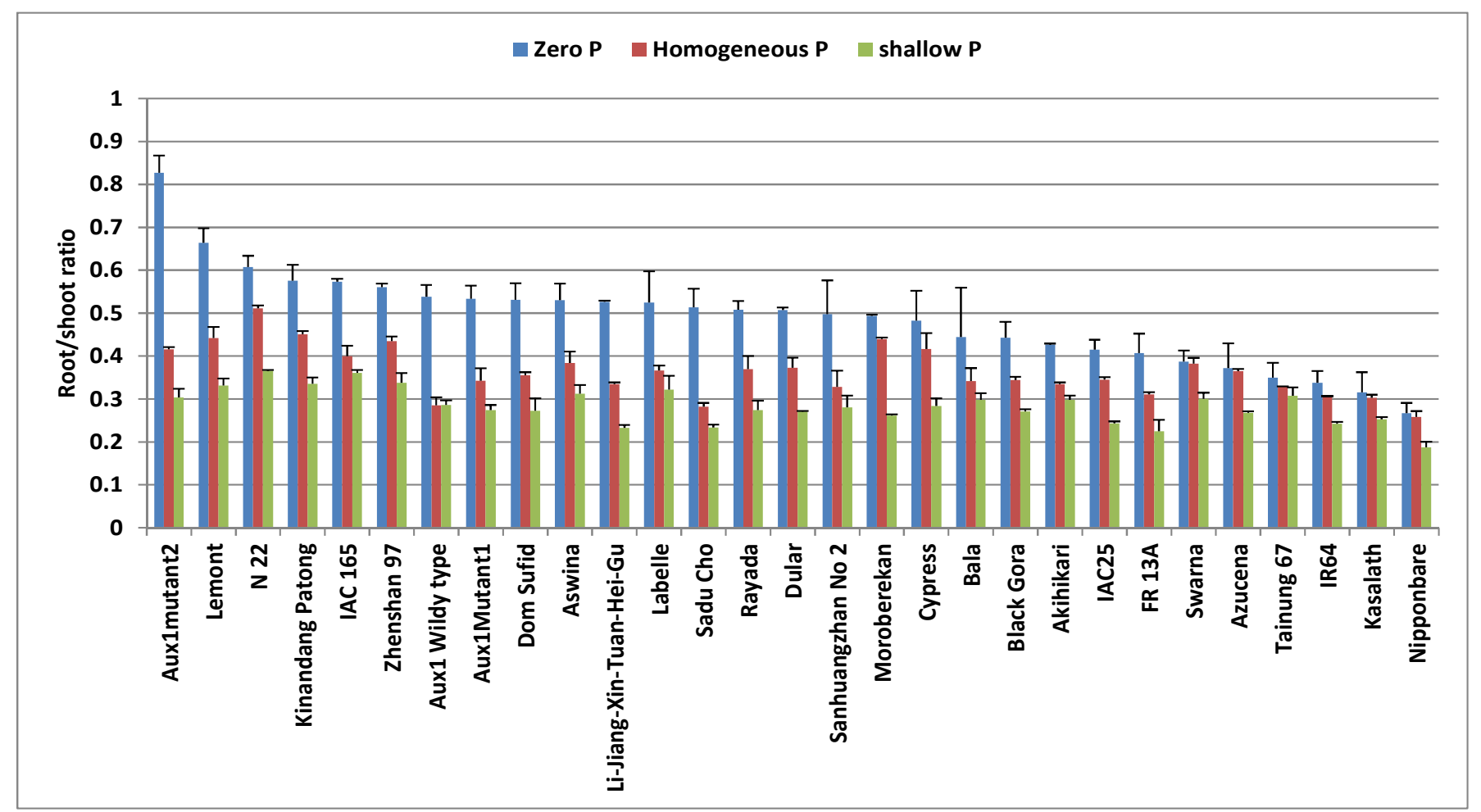

Figure 2. Root/shoot ratio of rice genotypes grown in a 25/75\% subsoil/sand mix either with (homogenous $P$ and shallow $P$, red and green respectively) or without rock phosphate (zero P, blue). $n=6$, Bar $=$ s.e.

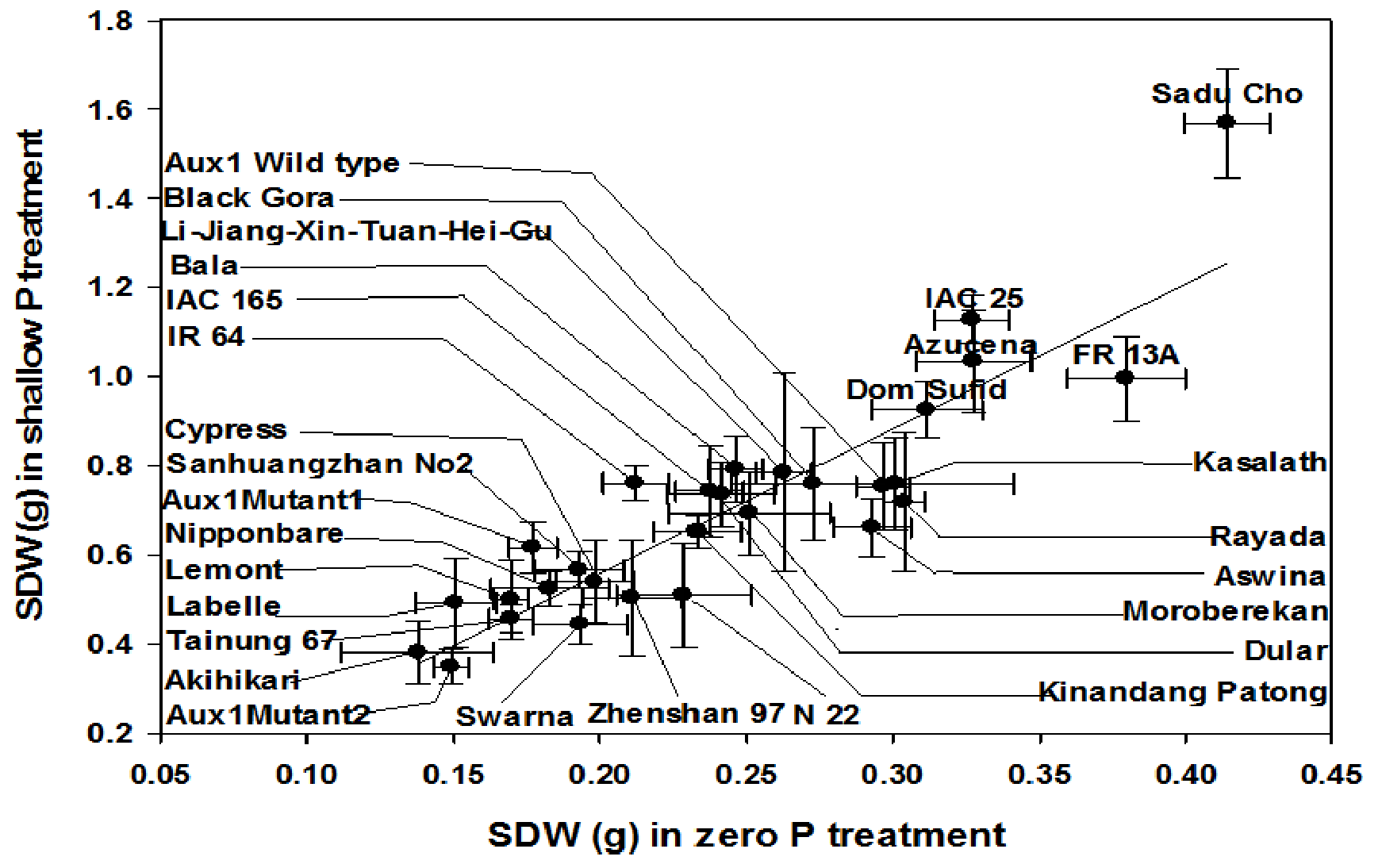

Figure 3. Scatter plot for SDW in zero P versus shallow P treatment. Bars are standard errors. 
Table 3. Correlation coefficients between SDW, total P, P concentration in shoot and P use efficiency within each treatment of rock P experiment. $n=11$.

\begin{tabular}{|c|c|c|c|c|c|c|c|c|c|c|}
\hline & \multicolumn{4}{|c|}{ SDW } & \multicolumn{3}{|c|}{ P use efficiency } & \multicolumn{3}{|c|}{$P$ conc. in shoot } \\
\hline & & Homo & Shallow & Zero & Homo & Shallow & Zero & Homo & Shallow & Zero \\
\hline & Homo & $0.941 * * *$ & $0.785 * *$ & $0.678^{*}$ & $-0.329 \mathrm{~ns}$ & $0.297 \mathrm{~ns}$ & $0.049 \mathrm{~ns}$ & $-0.136 \mathrm{~ns}$ & $0.049 \mathrm{~ns}$ & $-0.136 \mathrm{~ns}$ \\
\hline Iotal P in & Shallow & $0.923 * * *$ & $0.951 * * *$ & $0.779 * *$ & $-0.023 \mathrm{~ns}$ & $-0.086 \mathrm{~ns}$ & $-0.275 \mathrm{~ns}$ & $-0.542 \mathrm{~ns}$ & $-0.275 \mathrm{~ns}$ & $-0.542 \mathrm{~ns}$ \\
\hline $\mathrm{P}$ & Homo & $-0.041 \mathrm{~ns}$ & $-0.244 \mathrm{~ns}$ & $-0.389 \mathrm{~ns}$ & $-0.994 * * *$ & $-0.864 * * *$ & $-0.569 \mathrm{~ns}$ & & & \\
\hline concentration & Shallow & $-0.389 \mathrm{~ns}$ & $-0.549 \mathrm{~ns}$ & $-0.698 *$ & $-0.907 * * *$ & $-0.991 * * *$ & $-0.500 \mathrm{~ns}$ & & & \\
\hline in shoot & Zero & $-0.451 \mathrm{~ns}$ & $-0.584 \mathrm{~ns}$ & $-0.504 \mathrm{~ns}$ & $-0.620 *$ & $-0.544 \mathrm{~ns}$ & $-0.993 * * *$ & & & \\
\hline Puse & Shallow & $0.288 \mathrm{~ns}$ & $0.458 \mathrm{~ns}$ & $0.640 *$ & & & & & & \\
\hline & Zero & $0.501 \mathrm{~ns}$ & $0.630 *$ & $0.553 \mathrm{~ns}$ & & & & & & \\
\hline
\end{tabular}

*,**,*** Significant at $P=0.05, P=0.01$, and $P=0.001$, respectively; ns, not significant.

Table 4. ANOVA output and average of root parameters of eight selected rice genotypes grown in a 25/75\% subsoil/sand mix either with (homogenous $P$ or shallow P) or without rock phosphate (zero P) as a control. Mean $=6$.

\begin{tabular}{|c|c|c|c|c|c|c|c|c|c|}
\hline \multirow[b]{2}{*}{ Genotype } & \multicolumn{3}{|c|}{ Root length (m) } & \multicolumn{3}{|c|}{ Specific root length $\left(\mathrm{m} \mathrm{g}^{-1}\right)$} & \multicolumn{3}{|c|}{ Root surface area $\left(\mathrm{cm}^{2}\right)$} \\
\hline & Homo & Shallow & Zero & Homo & Shallow & Zero & Homo & Shallow & Zero \\
\hline Azucena & 38.6 & 38.4 & 21.1 & 169 & 111 & 172 & 499 & 590 & 333 \\
\hline Bala & 25.2 & 25.7 & 19.1 & 185 & 116 & 189 & 310 & 429 & 281 \\
\hline Black Gora & 19.8 & 19.2 & 37.8 & 152 & 149 & 276 & 261 & 285 & 317 \\
\hline Dular & 26.8 & 24.9 & 30.9 & 142 & 117 & 243 & 341 & 368 & 259 \\
\hline IAC 25 & 27.3 & 27.7 & 29.5 & 142 & 114 & 219 & 350 & 433 & 256 \\
\hline IR 64 & 28.1 & 26.9 & 18.6 & 182 & 127 & 269 & 345 & 409 & 253 \\
\hline Nipponbare & 18.2 & 12.9 & 26.6 & 156 & 152 & 560 & 224 & 181 & 181 \\
\hline Mean & 25.1 & 24.8 & 24.5 & 159 & 130 & 279 & 319 & 376 & 256 \\
\hline ANOVA\# & $\mathrm{F}$ & \multicolumn{2}{|c|}{$P$} & $\mathrm{~F}$ & \multicolumn{2}{|c|}{$P$} & $\mathrm{~F}$ & \multicolumn{2}{|c|}{$P$} \\
\hline $\mathrm{T}(2)$ & 0.02 & \multicolumn{2}{|c|}{0.980} & 13.78 & \multicolumn{2}{|c|}{0.000} & 17.81 & \multicolumn{2}{|c|}{0.000} \\
\hline $\mathrm{G}(7)$ & 1.99 & \multicolumn{2}{|c|}{0.099} & 1.63 & \multicolumn{2}{|c|}{0.175} & 12.77 & \multicolumn{2}{|c|}{0.000} \\
\hline $\mathrm{T} \times \mathrm{G}(14)$ & 1.32 & \multicolumn{2}{|c|}{0.268} & 1.34 & \multicolumn{2}{|c|}{0.258} & 1.60 & \multicolumn{2}{|c|}{0.150} \\
\hline $\mathrm{R}^{2}$ & $16.67 \%$ & & & $42.46 \%$ & & & $72.59 \%$ & & \\
\hline
\end{tabular}

Table 4. Continue.

\begin{tabular}{|c|c|c|c|c|c|c|c|c|c|}
\hline \multirow[b]{2}{*}{ Genotype } & \multicolumn{3}{|c|}{ Root volume $\left(\mathrm{cm}^{3}\right)$} & \multicolumn{3}{|c|}{ Average diameter (mm) } & \multicolumn{3}{|c|}{ Root tips (divided by 1000) } \\
\hline & Homo & Shallow & Zero & Homo & Shallow & Zero & Homo & Shallow & Zero \\
\hline Azucena & 5.1 & 7.2 & 4.2 & 0.41 & 0.49 & 0.49 & 14.2 & 14.2 & 9.1 \\
\hline Bala & 3.0 & 5.7 & 3.3 & 0.39 & 0.53 & 0.47 & 14.4 & 13.6 & 11.1 \\
\hline Black Gora & 2.7 & 3.4 & 2.7 & 0.42 & 0.47 & 0.33 & 11.5 & 10.6 & 34.6 \\
\hline Dular & 3.4 & 4.4 & 1.9 & 0.40 & 0.47 & 0.31 & 10.7 & 10.8 & 25.3 \\
\hline IAC 25 & 3.6 & 5.4 & 2.0 & 0.41 & 0.50 & 0.32 & 10.4 & 11.2 & 27.5 \\
\hline IR 64 & 3.4 & 5.0 & 2.7 & 0.39 & 0.48 & 0.43 & 11.1 & 10.3 & 7.7 \\
\hline Nipponbare & 2.2 & 2.0 & 1.3 & 0.39 & 0.44 & 0.27 & 10.3 & 7.2 & 22.4 \\
\hline Mean & 3.2 & 4.6 & 2.5 & 0.41 & 0.48 & 0.38 & 11.2 & 11.2 & 17.8 \\
\hline ANOVA\# & $\mathrm{F}$ & \multicolumn{2}{|c|}{$P$} & $\mathrm{~F}$ & \multicolumn{2}{|c|}{$P$} & $\mathrm{~F}$ & \multicolumn{2}{|c|}{$P$} \\
\hline $\mathrm{T}(2)$ & 22.23 & \multicolumn{2}{|c|}{0.000} & 6.81 & \multicolumn{2}{|c|}{0.005} & 2.01 & \multicolumn{2}{|c|}{0.156} \\
\hline G (7) & 9.12 & \multicolumn{2}{|c|}{0.000} & 1.17 & \multicolumn{2}{|c|}{0.355} & 0.64 & \multicolumn{2}{|c|}{0.716} \\
\hline $\mathrm{T} \times \mathrm{G}(14)$ & 0.93 & \multicolumn{2}{|c|}{0.543} & 0.83 & \multicolumn{2}{|c|}{0.635} & 0.78 & \multicolumn{2}{|c|}{0.683} \\
\hline $\mathrm{R}^{2}$ & $67.66 \%$ & & & $18.13 \%$ & & & $0.00 \%$ & & \\
\hline
\end{tabular}

\# ANOVA output and $\mathrm{R}^{2}$; T, rock phosphate treatment; G, genotype; degrees of freedom between brackets. $P$ value in bold is significant.

Table 5. ANOVA output and average of P element status in shoot of eleven rice genotypes grown in a 25/75\% subsoil/sand mix either with (homogenous $P$ or shallow $P$ ) or without rock phosphate (zero $P$ ) as a control. Mean $=6$.

\begin{tabular}{|c|c|c|c|c|c|c|c|c|c|}
\hline \multirow[b]{2}{*}{ Genotype } & \multicolumn{4}{|c|}{ Shoot $P$ concentration $\left(\mu \mathrm{g} \mathrm{g}^{-1}\right)$} & \multicolumn{2}{|c|}{ Total $P$ in shoot $(\mu \mathrm{g})$} & \multicolumn{3}{|c|}{$P$ use efficiency (PUE) } \\
\hline & Homo & Shallow & Zero & Homo & Shallow & Zero & Homo & Shallow & Zero \\
\hline Aux 1 wild type & 1968 & 2612 & 1039 & 1116 & 2024 & 309 & 0.51 & 0.39 & 0.98 \\
\hline Aux1Mutant1 & 1860 & 2745 & 996 & 651 & 1693 & 175 & 0.54 & 0.37 & 1.03 \\
\hline Aux1Mutant2 & 1834 & 2928 & 903 & 454 & 1031 & 121 & 0.55 & 0.34 & 1.14 \\
\hline Azucena & 1761 & 2584 & 733 & 1294 & 2689 & 231 & 0.57 & 0.39 & 1.39 \\
\hline Bala & 1750 & 2548 & 795 & 830 & 2027 & 194 & 0.57 & 0.40 & 1.28 \\
\hline Black Gora & 1449 & 2227 & 773 & 695 & 1623 & 214 & 0.71 & 0.46 & 1.30 \\
\hline IAC 25 & 1702 & 2421 & 764 & 1116 & 2733 & 248 & 0.59 & 0.42 & 1.34 \\
\hline
\end{tabular}




\begin{tabular}{|c|c|c|c|c|c|c|c|c|c|}
\hline \multirow[b]{2}{*}{ IR 64} & \multicolumn{4}{|c|}{ Shoot $P$ concentration $\left(\mu \mathrm{g} \mathrm{g}^{-1}\right)$} & \multicolumn{2}{|c|}{ Total $P$ in shoot $(\mu \mathrm{g})$} & \multicolumn{3}{|c|}{$P$ use efficiency (PUE) } \\
\hline & 1719 & 2508 & 889 & 877 & 1899 & 189 & 0.59 & 0.40 & 1.15 \\
\hline Kasalath & 1352 & 2171 & 801 & 600 & 1671 & 248 & 0.75 & 0.47 & 1.28 \\
\hline Nipponbare & 1862 & 2787 & 909 & 804 & 1464 & 164 & 0.54 & 0.36 & 1.11 \\
\hline Mean & 1739 & 2576 & 860 & 846 & 1902 & 209 & 0.59 & 0.40 & 1.20 \\
\hline ANOVA\# & F & & $P$ & $\mathrm{~F}$ & $\mathrm{P}$ & & $\mathrm{F}$ & 1 & \\
\hline $\mathrm{T}(2)$ & 874.17 & & 0.000 & 337.43 & & & 869.00 & & \\
\hline G (10) & 8.16 & & 0.000 & 8.07 & & & 6.92 & & \\
\hline T x G (20) & 1.39 & & 0.133 & 2.48 & & & 1.95 & & \\
\hline $\mathrm{R} 2$ & $90.30 \%$ & & & $79.85 \%$ & & & $90.19 \%$ & & \\
\hline
\end{tabular}

Element content in shoot $=$ element concentration in shoot $\left(\mathrm{mg} \mathrm{g}^{-1}\right) \times \mathrm{SDW}(\mathrm{g})$.

$\mathrm{PUE}=\mathrm{SDW}(\mathrm{g}) / \mathrm{P}$ in shoot $(\mathrm{mg})$.

$P$ value in bold is significant.

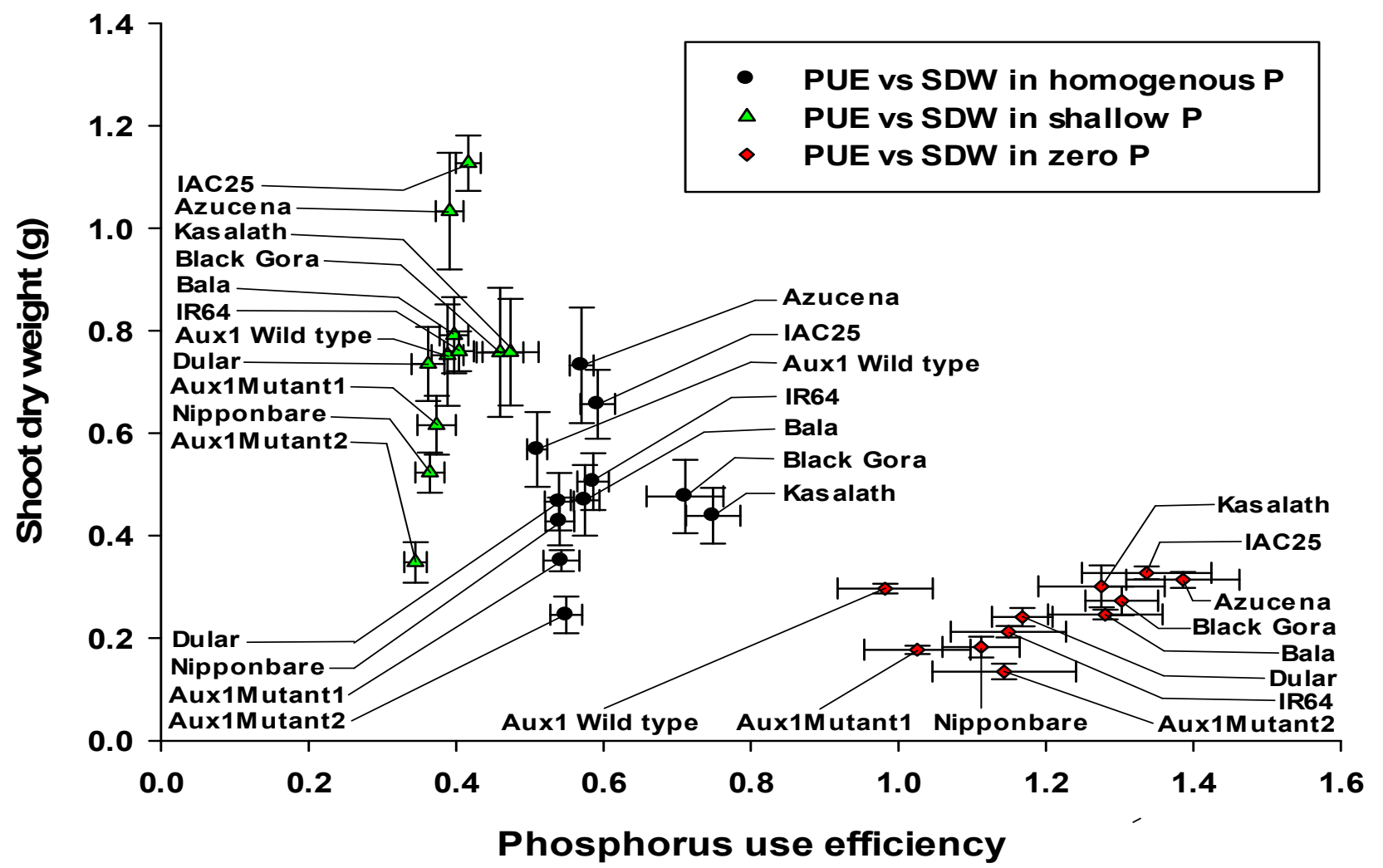

Figure 4. Scatter plot for SDW versus $P$ use efficiency [shoot dry weight $(g) / P$ in shoot (mg)] in homogenous $P$, shallow $P$ and zero $P$ treatment. Bars are standard errors.
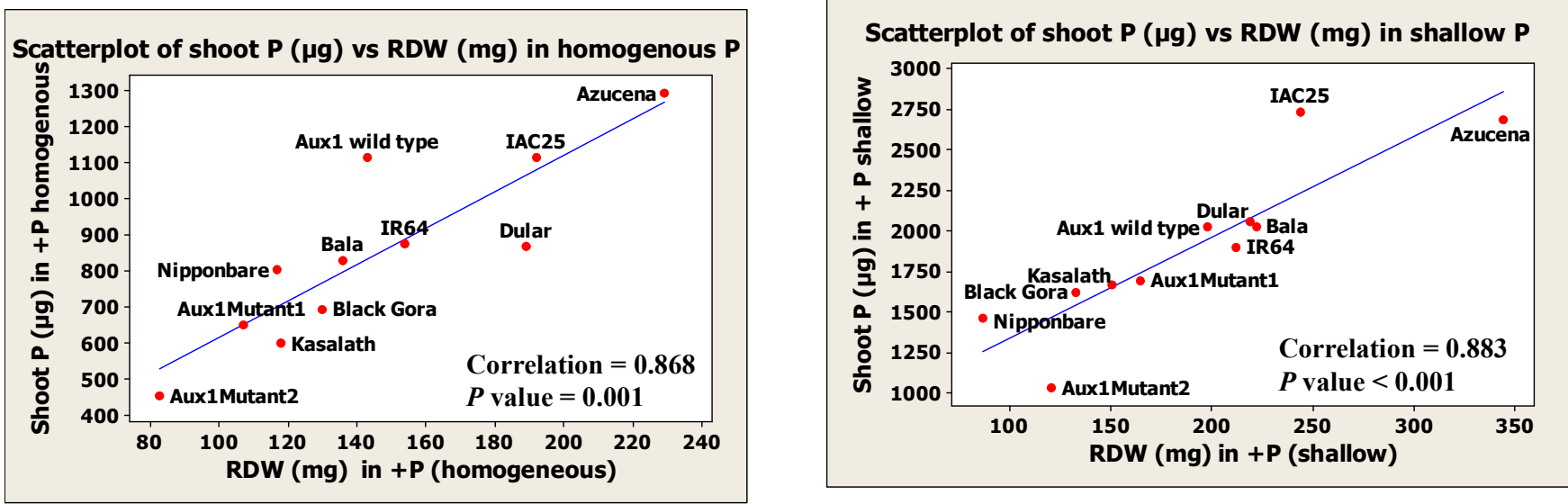


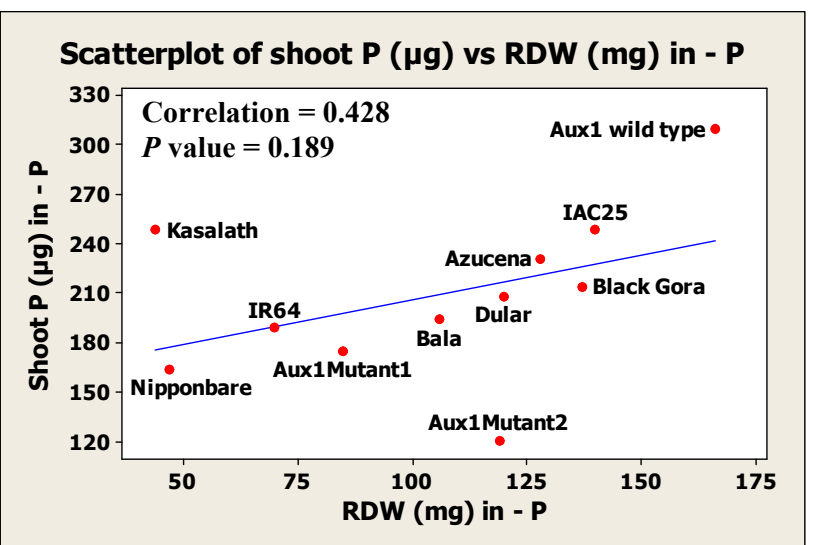

Figure 5. Scatter plot of total $P$ in shoot of eleven genotypes plotted against $R D W$ in each of three treatments (homogenous $P$, shallow $P$ and zero $P$ ) of rock phosphate experiment. The Pearson correlation coefficient and P-value for each graph are shown.

\section{References}

[1] H. R. von Uexku"11, and E. Mutert, 1995. Global extent, development and economic impact of acid soils. Plant Soil, 171: $1-15$.

[2] J. P. Lynch, 2005. Root architecture and nutrient acquisition. In: Bassirirad, H. (Ed.) Nutrient acquisition by plants: an ecological perspective, Ecological Studies, 181: 147-183.

[3] A. M. Bonser, J. Lynch and S. Snapp.1996. Effect of phosphorus eficiency on growth angle of basal roots in Phaseolus vulgaris. New Phytol., 132: 281-288.

[4] A.H. Fitter, 1991. The ecological significance of root system architecture. In: Atkinson, D. (Ed). Plant root growth. An ecological perspective. Oxford: Blackwell Scientific Publications, 229-246.

[5] J. Lynch, 1995. Root architecture and plant productivity. Plant Physiol., 109: 7-13.

[6] J. P. Lynch and K. Brown, 2001. Topsoil foraging: an architectural adaptation of plants to low phosphorus availability. Plant and Soil, 237: 225 - 237.

[7] J. V. Pothuluri, D.E. Kissel, D.A. Whitney and S.J. Thien,1986 Phosphorus uptake from soil layers having different soil test phosphorus levels. Agronomy Journal, 78: 991-994.

[8] G. Rubio, T. Walk, Z. Ge, X. Yan, H. Liao and J.P. Lynch, 2001. Root gravitropism and belowground competition among neighboring plants: a modeling approach. Annals of Botany, 88: $929-940$.

[9] S. E. Allen, 1989. Chemical Analysis of Ecological Materials Second edition, pp. 41-42.
[10] E.S.Marx, J. Hart and R.G. Stevens, 1999. Soil Test Interpretation GuideEC1478 Oregon State University Extension Service. Available from: http://ir.library.oregonstate.edu/xmlui/bitstream/handle/1957/1 4361/ec1478.pdf;jsessionid=EEA2557B584D5A31FABC3567 E3A43B64?sequence $=1$ [accessed on 10th February 2011].

[11] S. E. Allen, H.M. Grimshaw, J.A. Parkinson and C. Quarmby. 1974. Chemical analysis of ecological materials. 1st (Ed.) Blackwell Scientific Publications. Oxford. London.

[12] K. L. McNally, K. L. Childs, R. Bohnert, R. M. Davidson, K Zhao, V. J. Ulat, G. Zeller, R. M. Clark, D. R. Hoen; T. E. Bureau; R. Stokowski; D. G. Ballinger; K. A. Frazer, D. R. Cox, B. Padhukasahasram, C.D. Bustamante, D. Weigel, D.J. Mackill, R. M. Bruskiewich, G. Rätsch, C. R. Buell, H. Leung and J. E. Leach, 2009. Genomewide SNP variation reveals relationships among landraces and modern varieties of rice. Proc Natl Acad Sci., USA 106: 12273-12278.

[13] A. Henry, V. Gowda, R. Torres, K. McNally and R. Serraj, 2011. Variation in root system architecture and drought response in rice (Oryza sativa): Phenotyping of the Oryza SNP panel in rainfed lowland fields. Field Crop Res., 120: 205-214.

[14] S. Yoshida, D. A. Forno, J. H. Cock and K. A. Gomez, 1976. Laboratory manual for physiological studies of rice. IRRI, Los Banos, Philippines.

[15] H. R. Lafitte, M. C. Champoux, G. McLaren and J. C. O'Toole, 2001. Rice root morphological traits are related to isozyme group and adaptation. Field Crops Research, 71: 5770 .

[16] M.C. Drew,1975. Comparison of the effects of a localised supply of phosphate, nitrate, ammonium and potassium on the growth of the seminal root system, and the shoot, in barley. New Phytologist,75: 479-90.

[17] M. C. Drew,and L. R. Saker, 1978. Nutrient supply and the growth of the seminal root system in barley. III. Compensatory increases in growth of lateral roots, in rates of phosphate uptake and in response to a localised supply of phosphate. Journal of Experimental Botany, 29: 435-451.

[18] A. H. Fitter, 1985. Functional significance of root morphology and root system architecture. In: Fitter, A. H.; D. Atkinson; D. J. Read and M.B. Useher. (Eds). Ecological interactions in soil-plant, microbes and animals. London,Blackwell, 87-106.

[19] J. O. Hill, R. J. Simpson, A.D. Moore and D. F. Chapman, 2006. Morphology and response of roots of pasture species to phosphorus and nitrogen nutrition. Plant Soil, 286: 7-19.

[20] H. S. Kosar, M. A. Gill, T. A. Rahmatullah and M. Imran, 2002. Solublization of tri-calcium phosphate by different wheat genotypes. Pakistan J. Agric. Sci., 39: 273-277. 